\title{
ASPECTE CLINICE ŞI TERAPEUTICE ÎN MALFORMAȚIILE CARDIACE DUCTO-DEPENDENTE (PARTEA A II-A)
}

\author{
Alina-Costina Luca ${ }^{1}$, Andreea-Simona Holoc, Mirabela Subotnicu, \\ Constantin Iordache \\ ${ }^{1}$ Secția Clinică de Cardiologie Pediatrică, Spitalul Clinic de Urgențe pentru Copii \\ „Sf. Maria“", Universitatea de Medicină şi Farmacie „, Gr. T. Popa “, Iaşi
}

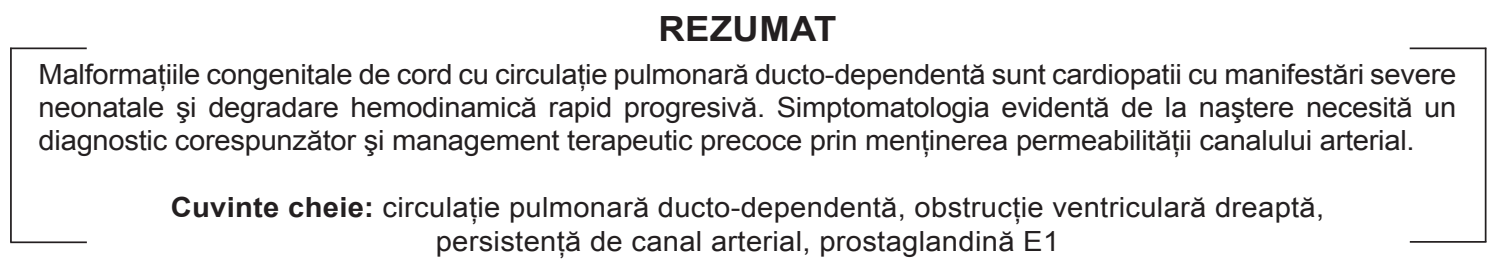

Malformațiile congenitale de cord cu circulație pulmonară ducto-dependentă sunt afecțiuni caracterizate prin obstrucția tractului de ejecție a ventriculului drept la care, pentru asigurarea circulației pulmonare, este necesar şuntul stânga-dreapta prin canalul arterial.

Malformațiile cardiace cu circulație pulmonară ducto-dependentă sunt:

- Stenoza arterei pulmonare

- Atrezia pulmonară cu sept interventricular întrerupt

- Tetralogia Fallot - formă severă

- Atrezie de valvă tricuspidă

- Anomalia Ebstein - formă severă

- D-Transpoziția vaselor mari.

\section{STENOZA ARTEREI PULMONARE}

În cadrul acestei malformații se realizează obstrucția severă a tractului de ejecție a ventriculului drept. În funcție de localizare poate fi valvulară, subvalvulară (infundibulară) sau supravalvulară.

Stenoza pulmonară critică se asociază cu hipertrofia sau hipoplazia ventriculului drept. Este necesară prezența unei mici comunicări la nivel atrial pentru a asigura un şunt dreapta-stânga prin foramen ovale. Şuntul dreapta-stânga la nivel atrial şi hipoxemia arterială depind de gravitatea stenozei pulmonare şi de hipoplazia ventriculului drept (1).

Atunci când stenoza este severă, şuntul dreaptastânga de la nivel atrial poate fi masiv, iar fluxul adecvat la nivelul pulmonilor este în functie de shuntul stânga-dreapta prin canalul arterial. În situația în care stenoza pulmonară este moderată, fluxul sangvin la nivel pulmonar este puţin influențat de închiderea canalului arterial (2).

La nou-născuții cu stenoză pulmonară critică, imediat după naştere apar tahipnee, cianoză şi dificultăți ale alimentației. În cazul pacienților cu stenoză pulmonară severă se observă bombarea regiunii precordiale; la palpare se decelează un impuls ventricular la nivelul marginii stângi a sternului şi freamăt sistolic în spațiul II intercostal stâng. Zgomotul II este dedublat, componenta pulmonară fiind întârziată şi diminuată. În formele severe zgomotul II este slab audibil, componenta aortică fiind acoperită de suflul continuu. La nivelul spațiului II-IV intercostal stâng se identifică suflu sistolic intens, rugos, crescendo-decrescendo. 
În cazul stenozei pulmonare severe, ECG arată deviație axială dreaptă şi hipertrofie ventriculară dreaptă. Ecocardiografia bidimensională în secțiunea ax scurt evidentiază deschiderea în dom a valvelor pulmonare, precum şi măsurarea inelului valvei pulmonare. Prin modul Doppler color se apreciază fluxul turbulent la nivelul trunchiului pulmonarei.

\section{ATREZIA PULMONARĂ CU SEPT INTERVENTRICULAR INTACT}

Obstrucția tractului de ejecție a ventriculului drept se datorează atreziei valvei pulmonare; în acest fel nu există comunicare între trunchiul arterei pulmonare şi ventriculul drept. Şuntul dreaptastânga de la nivel atrial depinde de şuntul stângadreapta de la nivelul canalului arterial. Deci perfuzia arterială pulmonară se produce prin canalul arterial, colaterale bronşice şi foramen ovale permeabil. Odată cu închiderea treptată a canalului arterial, fluxul pulmonar scade şi mai mult şi se instalează hipoxia severă şi acidoza, care se accentuează progresiv (3-5).

Frecvent apar crizele anoxice, dispneea cu polipnee agravată de efort (supt, plâns) şi insuficiența cardiacă dreaptă.

Simptomatologia este evidentă încă din primele 72 de ore de viață, cianoză, iniţial moderată, pentru ca ulterior aceasta să se accentueze, devenind extremă pe măsură ce canalul arterial se închide (4).

Examenul clinic relevă freamătul sistolic, iar la palparea abdomenului, hepatomegalia. La ascultația cardiacă se constată că zgomotul II este abolit. Pot fi prezente sufluri: aspirativ al insuficienței valvulare tricuspidiene şi sistolodiastolic de canal arterial permeabil (3).

Electrocardiografic sunt evidențiate axa electrică la dreapta $\left(+30^{\circ}\right.$ până la $\left.+90^{\circ}\right)$, hipertrofie atrială dreaptă şi hipertrofie ventriculară stângă (în caz de hipoplazie marcată a ventriculului drept).

Ecocardiografia bidimensională este examinarea de elecție în diagnosticul atreziei pulmonare cu sept interventricular intact. Aceasta pune în evidență valva pulmonară atrezică, morfologia valvei tricuspide, dimensiunea şi morfologia ventriculului drept. În plus, ecocardiografia Doppler color şi continuu permite estimarea regurgitării tricuspidiene, a presiunii ventriculului stâng şi persistența de canal arterial (16).

\section{TETRALOGIA FALLOT - FORMA SEVERĂ}

Această formă de boală aparține grupului de malformații cardiace cu obstrucție critică a circu- lației pulmonare; fluxul sangvin pulmonar este asigurat de canalul arterial deschis şi/sau de colateralele aorto-pulmonare.

Tabloul clinic este asemănător formei obişnuite de tetralogie Fallot, însă cianoza apare precoce, apar frecvente stări de rău hipoxic (valorile pulsoximetrice sunt egale la toate membrele, cu valori de $70-80 \%$, la oxigen atmosferic). Zgomotul II poate fi accentuat. Suflul sistolic ejecțional este înlocuit de un suflu continuu subclavicular stâng determinat de prezența canalului arterial permeabil $(6,7)$.

Electrocardiografic pune în evidență axa electrică deviată spre dreapta, hipertrofie ventriculară dreaptă sau biventriculară în caz de insuficiență cardiacă.

Ecocardiografia evidențiază în secțiunea parasternal ax lung vizualizarea discontinuității septului interventricular, determinarea gradului în care aorta este aşezată călare pe septul interventricular. Dacă inelul aortic se suprapune mai puțin de $50 \%$ din ventriculul stâng, putem pune diagnosticul de tetralogie Fallot, dacă acesta se suprapune peste 50\%, diagnosticul este de ventricul drept cu dublă cale de ieşire. În secţiunile transversale se poate evalua tractul de golire a ventriculului drept şi determina localizarea obstrucției (obstrucție subvalvulară, valvulară).

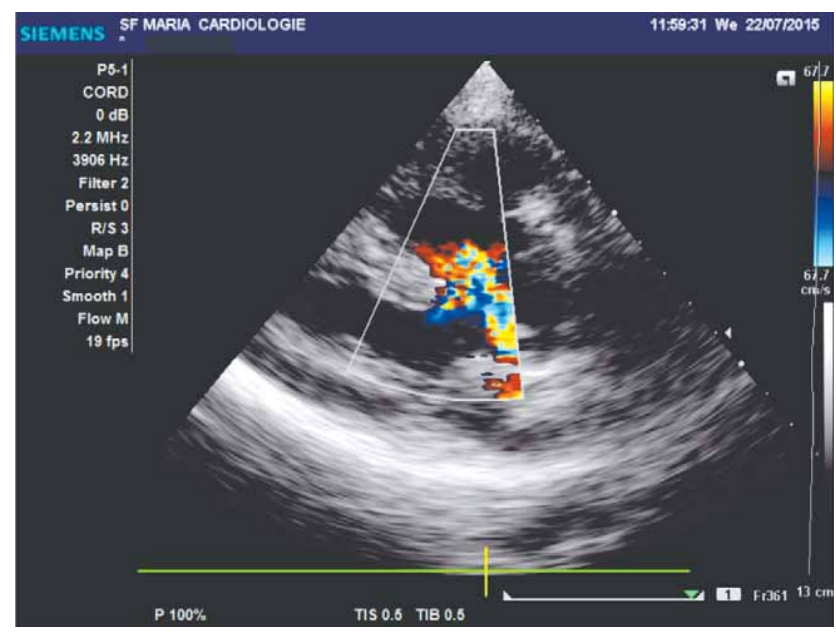

FIGURA 1. Pacient C.S, în vârstă de 15 ani Ecocardiografie - Tetralogie Fallot

\section{ATREZIA DE VALVĂ TRICUSPIDĂ}

Reprezintă o malformație congenitală cianogenă complexă caracterizată prin absența (agenezia) congenitală a valvei tricuspide, astfel încât nu se poate realiza comunicarea între atriul şi ventriculul drept.

Supraviețuirea este posibilă doar atunci când există un şunt dreapta-stânga la nivel atrial ce permite ca sângele venos venit din venele cave să 
se amestece în atriul stâng cu sângele arterial venit prin venele pulmonare; fluxul pulmonar este mult redus.

De asemenea, supraviețuirea este posibilă atunci când există un şunt stânga-dreapta care permite reîntoarcerea sângelui în circulația pulmonară prin DSV sau PCA.

După ce sângele venos se amestecă cu cel arterial pulmonar (sosit prin venele pulmonare) în atriul stâng, el trece în ventriculul stâng. Din ventriculul stâng, sângele pătrunde o parte în aortă (şi de aici, prin intermediul canalului arterial permeabil, în artera pulmonară), iar alta, prin defectul septal interventricular, în ventriculul drept.

$\mathrm{Cu}$ timpul creşte rezistența vaselor pulmonare, apare supraîncărcarea de volum a ventriculului stâng şi se instalează hipertensiunea pulmonară, apoi insuficiența cardiacă congestivă (8).

Clinic, atâta timp cât fluxul pulmonar este mult redus, apar stări de rău hipoxic şi poliglobulie (1). Când fluxul pulmonar este crescut apar dispnee constantă, infecții respiratorii recurente şi semne de insuficiență cardiacă.

Ascultator se decelează un zgomot II mult întărit în focarul pulmonarei (în situația asocierii cu persistența canalului arterial); suflu sistolic pe marginea stângă a sternului (în asocierea cu DSV) sau suflu continuu subclavicular stâng (în persistența canalului arterial) (9).

Radiografia cardio-pulmonară evidențiază un indice cardiotoracic mărit în cazul dilatării ventriculului drept sau stâng, aspectul circulației pulmonare variind în funcție de fluxul pulmonar. Electrocardiograma relevă hipertrofie atrială dreaptă (amplitudinea undei P $>2,5 \mathrm{~mm}$ în DII este prezentă la 75\% dintre pacienți), hipertrofie ventriculară stângă cu devierea axei QRS spre stânga.

Ecocardiografia transtoracică stabileşte diagnosticul, identificând absența conexiunii atrioven- triculare drepte, tipul atreziei, localizarea şi dimensiunea comunicării interatriale şi interventriculare.

\section{BOALA EBSTEIN - FORMĂ SEVERĂ}

Malformație congenitală de cord caracterizată prin diverse anomalii ale valvei tricuspide (implantare joasă a foiţelor septală şi posterioară), cu mărirea de volum a atriului drept şi micşorarea de volum a ventriculului drept (cea mai mare parte fiind atrializat).

Şuntul dreapta-stânga la nivel atrial este cel care reflectă gradul hipoxemiei. Rezistențele vasculare crescute duc la creşterea post-sarcinii ventriculului drept, astfel încât şuntul dreapta-stânga devine masiv şi implicit hipoxemia devine severă (frecvent apar crize hipoxice), cu cianoză de diferite grade, dispnee şi tahicardie (10).

Când comunicarea prin canalul arterial se închide, hipoxemia se accentuează şi apar acidoza respiratorie şi decesul. În lipsa comunicărilor interatriale apare insuficiența cardiacă dreaptă cu hepatomegalie.

Clinic, în formele severe cianoza apare din primele zile de viață; zgomotul II este dedublat, ritm în 3 sau 4 timpi; suflu pansistolic de regurgitare tricuspidiană, freamăt sistolic, hepatomegalie de stază (11).

Pe electrocardiogramă sunt prezente semne de suprasolicitare atrială dreaptă: unde P înalte, ascuțite, tulburări de ritm supraventricular, prezența undei delta indică existența sindromului WPW (Fig. 2) (12).

Ecocardiografia transtoracică - apical 4 camere este secțiunea de elecție în diagnosticul anomaliei Ebstein. Se apreciază gradul de atrializare a ventriculului drept, deplasarea şi distorsiunea foițelor tricuspidiene, precum şi gradul de apropiere al foitelor anterioare a valvei tricuspide la ventriculul

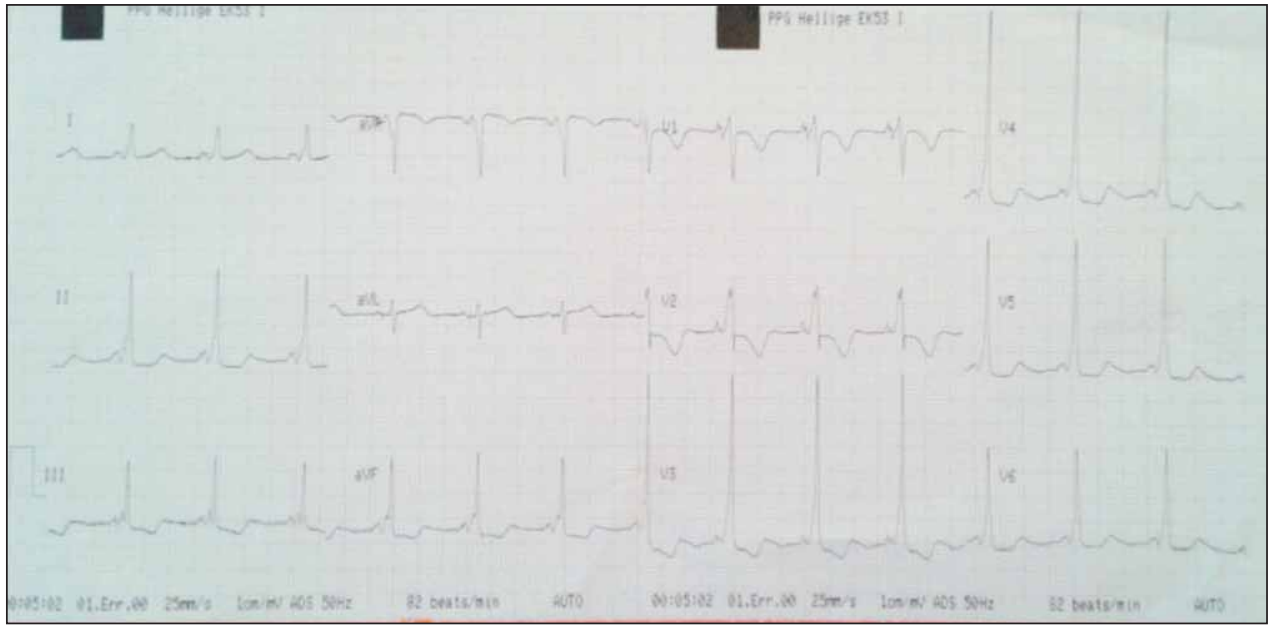

FIGURA 2. Pacient S.A.G, 11 zile - electrocardiograma in boala Ebstein: unda delta prezentă în DI,DII, V3, V4, V5 (sindrom WPW) 
drept. Prin Doppler color se poate determina prezența şi mărimea şuntului interatrial (Fig. 3).

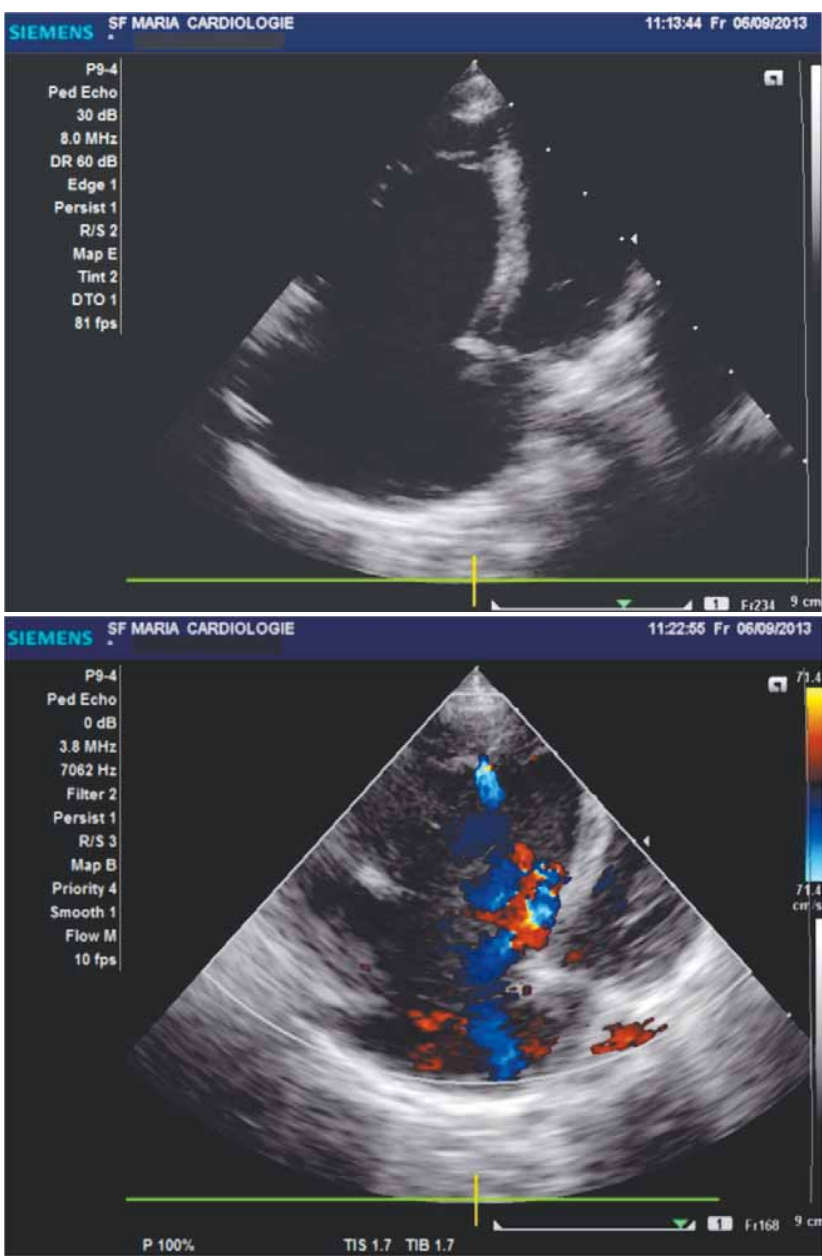

FIGURA 3. Pacient S.A.G, 11 zile: ecocardiografie apical 4 camere - anomalie Ebstein formă severă

\section{D-TRANSPOZIȚIA VASELOR MARI}

Se defineşte prin discordanţa ventriculo-atrială, în sensul că aorta emerge din ventriculul drept morfologic, iar artera pulmonară emerge din ventriculul stâng morfologic.

Particulare sunt două elemente:

- Aorta este situată anterior față de artera pulmonară;

- Există concordanță atrioventriculară.

\section{Hemodinamică}

Cele două circulații, sistemică şi pulmonară nu sunt în serie, ci paralele, adică sângele venos sistemic ajunge în atriul drept, apoi în ventriculul drept şi ulterior în aortă, iar sângele oxigenat din plămâni ajunge în atriul stâng, apoi în ventriculul stâng, de unde trece în artera pulmonară.

Copilul poate supraviețui dacă există şunturi între cele două circulații prin canalul arterial şi foramen ovale. După naştere, rezistențele pulmonare scad şi prin canalul arterial sângele arterial desaturat trece din aortă în artera pulmonară. Se produce astfel o hipoxie severă cu saturații de oxigen de 30$60 \%$ şi o presiune pulmonară de $15-40 \mathrm{~mm} \mathrm{Hg}$. Numai prin existența unui foramen oval permeabil sângele oxigenat de la venele pulmonare ajunge în atriul stâng şi apoi în atriul drept şi de aici în circulația sistemică (şunt bidirecțional), împiedicând astfel apariția cianozei, dar conducând la instalarea precoce a insuficienței cardiace congestive $(13,14)$.

Alte defecte asociate necesare pentru supraviețire sunt defectele septale interatrial şi interventricular.

\section{Clinic}

Iniţial apar semne de hipertensiune arterială pulmonară precoce şi cianoză (rebelă la administrarea de oxigen), a cărei intensitate este în funcție de comunicările dintre cele două părți ale inimii.

Când PCA este larg şi se asociază şi DSV, tabloul clinic este cel de insuficiență cardiacă congestivă (dispnee stabilă, tahipnee, transpirații, geamăt, plâns răguşit).

În funcție de malformația cardiacă asociată, suflul sistolic poate fi intens (defect septal interventricular) sau sistolo-diastolic (persistență de canal arterial). Dilatarea ventriculară se asociază cu galopul protodiastolic (zgomotul III), iar dilatarea atrială cu galop presistolic (15).

\section{Paraclinic}

Electrocardiograma arată devierea axei spre dreapta, hipertrofie ventriculară dreaptă (R amplu în V1 şi S adânc în V6). Radiografia cardio-pulmonară evidențiază un mediastin superior îngustat, silueta cardiacă cu formă ovoidală clasică de ,egg on a string" şi desen pulmonar accentuat.

Ecocardiografia transtoracică în secțiunea parasternal ax scurt la nivelul marilor vase evidențiază vasele mari cu dispoziție paralelă, aorta situată anterior şi la dreapta faţă de artera pulmonară. Ecografia Doppler apreciază gradientul transvalvular pulmonar.

\section{TRATAMENTUL FARMACOLOGIC AL MALFORMAȚIILOR CONGENITALE CARDIACE CU CIRCULAȚIE PULMONARĂ DUCTAL DEPENDENTĂ}

\section{Se recomandă}

Administrarea cu prudență a oxigenului pentru a evita închiderea canalului arterial, menținând sa- 
turațiile la mâna dreaptă peste $75 \%$ pentru micşorarea rezistenței vasculare pulmonare.

Menținerea permeabilității canalului arterial prin administrarea de Prostaglandină E1: 0,15$0,20 \mu \mathrm{g} / \mathrm{kgc} / \mathrm{min}$ cu suplimentarea $0,20 \mu \mathrm{g} / \mathrm{kgc} /$ min la fiecare 15 minute până la obținerea efectului (timpul de înjumătățire este de 30 de secunde, aşadar este indicată administrarea continuă a perfuziei); supravegherea atentă a statusului neuro-psihic, a frecvenței cardiace, a tensiunii arteriale, a statusului respirator, traseu ECG pe timpul perfuziei este foarte importantă din cauza apariției efectelor adverse: convulsii, bradipnee, hipotensiune, tahicardie, bloc atrioventricular grad II, tahicardie supraventriculară, fibrilație ventriculară, stop cardiorespirator (17).

Când circulația pulmonară este suprasolicitată (tensiunea este normală sau crescută) se indică inhibitori ai enzimei de conversie a angiotensinei Captopril 1 mg/kge $(18,19)$.

Dacă tensiunea arterială este scăzută, se indică inhibitori ai fosfodiesterazei - Sildenafil 0,5-2 mg/ kgc/doză.

Se asociază diuretice - Spironolactonă $1 \mathbf{~ m g} /$ kge în 1-3 prize; în formele severe de insuficiență cardiacă congestivă se asociază Furosemid 1 mg/ kgc/doză, până se obține o diureză mai mare de 3 $\mathrm{ml} / \mathrm{kcg} /$ oră, doză care se repetă 6-12 ore; în lipsa efectului doza se repetă după 2 ore.

Se va administra până la volumul normal volumexpander (ser fiziologic 0,9\% sau Ringer lactat) în cantitate de $10 \mathrm{ml} / \mathbf{k g c}$ intravenos.

Acidoza metabolică severă va fi tratată cu bicarbonat de sodiu $4,2 \%$ (în cantitate de $2 \mathbf{~ m E q} / \mathbf{k g c} /$ doză) intravenos foarte lent, la o ventilație adecvată.

Administrarea de prostaglandină E1 pentru menținerea deschisă a canalului arterial. Doza inițială este de 0,05-0,1 $\mathbf{~ m c g / l g c / m i n . ~}$

\section{CONCLUZII}

Simptomatologia critică prezentă la naştere şi deteriorarea progresivă impun un diagnostic precoce pentru a preveni apariția complicațiilor. Ecocardiografia este un examen paraclinic important în diagnosticul malformațiilor congenitale cardiace cu circulație pulmonar dependentă fiind indispensabilă asupra dispensarizării copilului şi urmăririi deteriorării cardiace. Aşadar, un examen clinic atent, confirmarea diagnosticului prin metode paraclinice cât mai precise, menținerea permeabilității canalului arterial şi dirijarea către un centru specializat în vederea intervenției chirurgicale sunt esențiale în gestionarea acestor cazuri. 